\title{
Adopting Distributed Ledger Technology (DLT) For The Sustainable Construction Industry: Evaluating The Barriers Using Ordinal Priority Approach (OPA)
}

\section{Mahsa Sadeghi}

Southeast University School of Civil Engineering

\section{Amin Mahmoudi}

Southeast University School of Civil Engineering

Xiaopeng Deng ( $\nabla$ dxp@seu.edu.cn)

Southeast University School of Civil Engineering https://orcid.org/0000-0002-2987-505X

\section{Research Article}

Keywords: Construction 4.0, Building Information Modeling (BIM), Distributed Ledger Technology (DLT), blockchain, sustainability, Ordinal Priority Approach (OPA), multiple attributes decision-making (MADM)

Posted Date: June 18th, 2021

DOl: https://doi.org/10.21203/rs.3.rs-566565/v1

License: (c) (i) This work is licensed under a Creative Commons Attribution 4.0 International License. Read Full License 


\section{Abstract}

Construction 4.0 has become a buzzword since the penetration of building information modeling (BIM), cyber-physical systems, digital and computing technologies into the construction industry. Among emerging technologies, Distributed Ledger Technology (DLT), or blockchain, is a powerful business enhancer whose potential can disrupt projects, AEC (Architecture, Engineering and Construction) firms, and construction supply chain, and in a broader sense, the whole construction industry. This technology has not reached the plateau of productivity due to several barriers and challenges. Previous studies have started to investigate the barriers to implementing DLT in various sectors and segmentations. However, we still need further surveys in the construction industry. This study evaluates the applicability of identified challenges and barriers based on a sustainability perspective. Precisely, we will answer which challenges need to be addressed for the sustainability of the construction industry. To meet the research objective, the Ordinal Priority Approach (OPA) in multiple attributes decision-making (MADM) was utilized. This novel method determines the importance of the sustainability attributes and barriers simultaneously. The results show that DLT implementation needs i) infrastructure for data management, ii) advanced applications and archetypes, and iii) customers' demand, interest, and tendency, and iv) taxation and reporting. Solving high-ranked challenges is the key to social sustainability from the aspects of 'supply chain management and procurement,' 'transparency, anti-corruption, and anti-counterfeiting,' and 'fair operation and honest competition.'

\section{Introduction}

The construction industry (or $A E C$ ) is one of the driving forces of economic growth due to various market players, construction projects, complex supply chains, and extensive value networks (WEF, 2016). Despite its crucial role, it has long been dealing with low productivity, delayed payments, squeezed profit margins, poor regulatory compliance, lack of trust, and poor communication among stakeholders (Li et al., 2019; Hunhevicz and Hall, 2020). The problems above prevent the construction industry from being prepared for digital transformation and benefits offered by emerging technologies. According to (McNamara and Sepasgozar, 2021), industry 4.0 concept helps the construction industry to keep up with other sectors in term of performance improvement. Distributed ledger technology (DLT), or blockchain (BCT), is one of the industry 4.0 constituents that has received increasing interest in the last decade. It provides businesses and industries with novel solutions based on trust, transparency, connectivity, security, traceability, and automation (Ozdemir et al., 2020).

A review of the existing literature shows that academia and practitioners have intensively stressed DLT/BCT and its prospect use-cases, mainly 2018 afterward (Wamba and Queiroz, 2020). Saberi et al. (2018) and Lohmer and Lasch (2020) used a similar framework for categorizing barriers based on intra-/inter-organizational, system-related, technological, and external aspects. Biswas and Gupta (2019) developed a framework for identifying barriers to successfully implementing blockchains in various industries and services, using the decision making trial and evaluation laboratory (DEMATEL) technique. According to the findings, the most influencing obstacles are market-based risks and scalability issues. 
And, the most influenced barriers are high sustainability costs and poor economic behavior. Helliar et al. (2020) conducted a comprehensive literature review and explored 28 barriers of blockchains diffusion for permissionless and permissioned types. Bag et al. (2020) explored barriers to blockchain adoption in green supply chain management (GSCM). The findings show that the most influencing barriers are 'cultural differences among partners' and 'lack of management vision.' The most influential barriers are 'workforce obsolescence and hesitation' and 'collaboration challenges' in GSCM. Öztürk and Yildizbaşi (2020) discussed 18 barriers in the field of supply chain management. According to the findings, high investment costs, data security, and utility are important factors.

Mathivathanan et al. (2021) identified nine barriers to DLT adoption in business supply chains. The results reveal that 'lack of business awareness' and 'low familiarity with blockchain's potentials in supply chains' are the most critical barriers that impede blockchain adoption. In the manufacturing supply chains context, Vafadarnikjoo et al. (2021) used the neutrosophic analytic hierarchy process (N-AHP) to analyze five barriers to blockchain technology. The authors found that 'transaction-level uncertainties' and 'usage in the underground economy' are the most influential ones. Kouhizadeh et al. (2021) utilized the technology-organization-environment framework (TOE) framework, with slight modifications, to identify critical barriers in the field of blockchain adoption for sustainable supply chain management (SSCM). The authors analyzed barriers and evaluated interdependencies among them using the DEMATEL technique. The results showed that supply chain and technology are the most challenging factors from academicians' and experts' perspectives. Kumar et al. (2021) identified barriers that impede the successful implementation and operation of industry 4.0 technologies for supply chains considering the circular economy approach. The authors used a hybrid approach of AHP and ELimination Et Choice Translating REality (ELECTRE) to rank barriers and sustainability parameters. The results show that 'lack of budget' and 'lack of strategic plan' are major barriers to technology application.

Farooque et al. (2020) utilized fuzzy DEMATEL to analyze barriers that impede blockchain adoption in life cycle assessment (LCA). According to obtained results, the immature underlying technology and technical issues for collecting real-time supply chain data are the highest in net cause-effect values. In parallel, lack of organizational procedures and government regulations in using technology are the highest in prominence. In the construction context, Yang et al. (2020) discussed the challenges of adopting blockchain technology. According to the authors, the main challenges are variations of the construction industry, identity, cost and complexity in adoption, and scalability. Few researchers have addressed the barriers to successful DLT adoption at the time of writing, particularly in the construction industry and related fields. To address this research gap, the present study focuses on adopting distributed ledger technology (DLT) for the sustainable construction industry and evaluating the barriers using ordinal priority approach (OPA) in multiple attributes decision-making (MADM). To achieve the research objective, first, we formulated the following research questions (RQs):

RQ 1. What are the barriers faced leveraging DLT in service sectors, particularly the construction context?

RQ 2. How DLT contributes to sustainability, and what are the sustainability attributes? 
RQ 3. Which barriers are the most critical to achieving sustainability in the construction industry?

For this, we explored factors from previous literature. To assess the applicability of factors in the construction context, we collected opinions of experts specialized in emerging technologies, construction, and related disciplines. This study also used a new tool in MADM context which is known as the OPA. OPA calculates the weights and ranks of experts, attributes, and barriers simultaneously. According to the mentioned novelties, the current study will help policymakers and practitioners who want to be earlymovers in the construction industry by embracing new technologies (i.e., DLT/ BCT). This research will also broaden scholars' horizons about critical barriers within DLT implementation as references for further examination. The rest of this study is organized into six sections. After the introduction, the literature review has been provided in Sect. 2. Then, Sect. 3 is allocated to methodology. Section 4 presents the research framework, and Sect. 5 illustrates a case study and related discussion. Finally, Sect. 6 provides the conclusion.

\section{Literature Review}

\subsection{Distributed Ledger Technology (DLT) for sustainability}

Distributed Ledger Technology (DLT), or blockchain (BCT), is a decentralized database and shared computing infrastructure. The primary mission of DLT/BCT is generating, verifying, updating, sharing, transferring, and storing transactions within distributed ledgers without any trusted intermediaries (Nakamoto, 2008). Ozdemir et al. (2020) summarized key features of blockchains in speed, traceability, trust, security, disintermediation, immutability, transparency, and automation. According to Mougayar and Buterin (2016), DLT's features are crucial for basic functions like smart assets, timestamping, multisignature transactions, smart contracts, and smart oracles. To date, this technology has experienced four consecutive versions: Blockchain 1.0 (cryptocurrency), Blockchain 2.0 (smart contracts), Blockchain 3.0 (distributed applications), and Blockchain 4.0 (interoperability among industry 4.0-based applications (Bodkhe et al., 2020). This evolutionary trend shows that DLT can play a critical role in the 'internet of value.' Within distributed ledgers, any real-world value _ including i) intangible (i.e., trust, ownership, and identity), ii) tangible (i.e., real estate, equipment, and currency), and iii) obligations (i.e., contracts and agreements) _ can be digitalized and exchanged (Nawari and Ravindran 2019).

Blockchain is a well-recognized type of DLT. Other alternatives, with the similar underlying technology, are hash graph, directed acyclic graph (DAG), Tangle, Holo-chain, and Radix (O'Dair, 2018). Hence, throughout the current study, the terms 'DLT' are referred to as any form of distributed ledgers, including blockchain technology. In the context of the DLT implementation, Hilton et al. (2019) proposed a roadmap with defined deliverables, such as i) assessing viability and feasibility of use-cases, ii) developing a minimum viable product (MVP), and building 'proof of concept,' and iii) continuous scaling and running pilot blockchain solution in a real environment. Janssen et al. (2020) discussed a conceptual model for blockchain adoption based on process, institutional, market, and technological dimensions (PIMT). In the same line of thinking, Yang et al. (2020) presented an application framework for the construction 
industry. The authors asserted that four aspects of the regulation, industry trust, business, and technique, should be considered for a successful DLT adoption.

The previous studies show that there are various areas for DLT application, such as i) smart cities and built environment (Marsal-Llacuna, 2018), ii) logistics, procurement, and supply chain management (Fosso Wamba et al., 2020; Kouhizadeh et al., 2021), iii) smart homes, as microgrids in energy trading (Petri et al., 2020), iv) project value delivery, payments, finance management, and investment consistency (Penzes, 2018; Hunhevicz and Hall, 2020), v) dispute resolution, tendering, and construction bid competition (Barima 2017; Leng et al. 2020), vi) real-estate and land registry (Bürer et al., 2019), vii) project bank accounts (PBAs) (Li et al., 2019) and decentralized autonomous organization (DAO) (Nawari and Ravindran 2019).

DLT promises to enhance time efficiency, quality, productivity, cost savings, and transparency within processes and activities (Mougayar and Buterin 2016). Considering DLT's features and potentials, this technology can be employed for sustainable development goals (SDGs). Early application in the finance and banking industry shows that DLT/BCT has been a driving force of a new economic structure. With that in mind, DLT becomes highlighted for social and environmental sustainability, as well. However, this technology is relatively nascent, and it takes a while for companies to find out how to utilize DLT potentials for the sake of sustainability. The research works by De Giovanni (2020), and Kouhizadeh et al. (2021) emphasized the role of blockchain and smart contracts in the sustainability of supply chain management (SCM). Wamba \& Queiroz (2020) stressed the convergence of blockchain and industry 4.0 technologies (i.e., big data, artificial intelligence (Al), internet of things (IOT), robotics, and so forth). This combined effort can result in a sharing economy, transparent operations, and sustainable supply chain management (OSCM). Nandi et al. (2020) discussed how blockchain technology and the circular economy principle contribute to the localization, agility, and digitization (LAD) and sustainability of supply chain management.

Related studies show that DLT, directly or indirectly, contributes to sustainability. In this regard, we identified 30 sustainability attributes in the following clustering: two project sustainability, twelve social attributes, eight environmental attributes, eight economic attributes. Detailed information and definitions are provided in Appendix A, Table A2. These criteria will be analyzed later in a case study (Sect. 5) using the OPA.

\subsection{Barriers facing DLT implementation in the AEC ecosystem}

As mentioned in the introduction, some studies were discussing barriers facing DLT implementation in various sectors. According to Yang et al. (2020), one of the high-potential areas for future research directions is the challenges of adopting blockchain technology in the construction industry. We still need further surveys to assess general and (non)construction-specific challenges and their applicability in the 
AEC industry. In this regard, we identified challenges from previous studies. Based on their roots and time of occurrence, we categorized them in project, organization, market, and industry levels.

Project level: Although employing blockchain systems for project management activities is still too early (Yang et al., 2020), it seems that some challenges emerge from operations, project activities, and processes. In this regard, 11 barriers have been identified, mostly in project integration, procurement, communication, time, and cost.

P1. Abuse and fraud: Installing faulty systems and software bugs can increase intentional abuse, fraudulent activities, and human error at the application level (i.e., payment and procurement practices) (Helliar et al., 2020).

P2. Manual processes and traditional practices: Digitalizing will challenge manual processes (e.g., purchase order, accounting, invoicing, and payments) and traditional practices controlled by centralized systems (Hofmann et al., 2018).

P3. Irreversibility and immutability of the process: By employing smart contracts and automated processes, the chance for human intervention in changing coded documents and transactions will be reduced significantly (Biswas and Gupta, 2019; McNamara and Sepasgozar, 2021).

P4. Authenticity, consistency, and legitimacy of data: The excellent performance of distributed ledger is closely related to the availability and reliability of uploaded data to prevent any fraudulent activities (Li et al., 2019).

P5. Infrastructure for data management: In projects, there is a high need for robust devices and collaborators with minimum malfunctions, manipulation, and cyber-attacks. This paves the way for collecting, clustering, synchronizing, and storing data with maximum integrity and consistency (Penzes, 2018).

P6. Contractual standards: When technology embeds into project management practices/processes, a standard contractual model with detailed milestones, deliverables are required to develop a smart contract (Penzes, 2018).

P7. Multiple chains and private systems: When multiple blockchains versions and systems (i.e., enterprise resource planning (ERP)) engaged in a blockchain-based solution, poor integrity hampers crosstransactions and causes attacks, human errors, data loss, and fragmentation (Hofmann et al., 2018; Helliar et al., 2020).

P8. Fragmentation and complexity of activities: DLT implementation for the complicated and fragmented process (i.e., procurement and supply chain activities) requires significant effort, time, and resources (Hofmann et al., 2018). 
P9. Scalability problems: Several factors intensified scalability issues: i) data transmission latency, ii) transaction processing rate (throughput), and iii) duplicate information storage (Biswas and Gupta, 2019; Yang et al., 2020).

P10. Lower external accountability control: Blockchain-based financing tools carries uncertainty and risks due to lower external accountability controls on them (Mougayar and Buterin, 2016).

P11. Financing models and debt instruments: There are various novel mechanisms to raise funds through blockchain-based platforms, such as supply chain finance (SCF). Lack of managerial perception and mindset about new fundraising tools in distributed platforms explain why decision-makers and practitioners hesitate and resistant to adopt these novel DLT-based solutions for their businesses' needs (Hofmann et al., 2018).

Organization level: Organizational factors are often considered the most influential determinants of IT innovation adoption in firms and organizations (Clohessy and Acton, 2019). Having this in mind, 13 barriers and challenges have been identified, majorly in men, machines, methods, materials, and money (5Ms) aspects.

01. Organizational considerations: To reap DLT/blockchain's benefits, there is a high to managerial support, staffs' cooperation and mind-sets, stakeholders' trust, and organizational maturity (Clohessy and Acton, 2019).

02. New business model: Organizations should determine the necessity of blockchain technology as their strategic needs and enhance services/products for customers accordingly (Penzes, 2018; Clohessy and Acton, 2019).

03. Shared governance: The governance model is an integral part of an intra-/inter-organizational collaboration that determines how the platform is structured and controlled by parties (Penzes, 2018; Helliar et al., 2020).

04. Financial constraints and cost of adoption: Although platforms are mostly free open-source, it is required to consider initial investment, costs breakdown structure, and prediction of cost-savings (Sawhney et al., 2020).

05. Uncertain return of investment (ROI): Construction companies need a clear picture of the value proposition and (non)financial benefits offered by DLT adoption (Sawhney et al., 2020).

06. Digital representation of real-world objects: A wide range of stakeholders and assets are involved in a construction ecosystem. For easy value exchange, organizations need to give access to people, create a native smart asset, or connect physical assets to the blockchain using RFID tags and digital identity (Mougayar and Buterin, 2016; Yang et al., 2020). 
07. Negative perception and insufficient understanding: Organizations may take a wait-and-see attitude and postpone adoption until they gain in-depth knowledge of DLT/blockchain's potential (Barima, 2017; Kshetri, 2017; Saberi et al., 2018).

08. Scarcity in multidisciplinary experts and developers: Organizations need multi-disciplined professionals and fresh new talent in cryptography science, smart contract and legal affairs, construction projects, and DLTs for successful implementation (Li et al., 2019; Yang et al., 2020).

09. Legacy systems: Organizations need modern computer architecture and specialized equipment to reap DLT's benefits. This can be obtained through replacing or upgrading existing systems (Mougayar and Buterin, 2016).

010. System robustness and full technology stack: Adoption needs a set of technology stack (i.e., software, hardware, middleware, and infrastructure) and continuous internet connectivity (Mougayar and Buterin, 2016; Li et al., 2019).

011. Lack of advanced applications and archetypes: The underlying technology is nascent; and, producing a killer-applications and successful archetypes takes a while (Mougayar and Buterin, 2016).

012. Wide rollout and large-scale technology adoption: Shifting from ideation to real-world applications needs a list of requirements, such as investment, the firms' readiness, and training staff (Sawhney et al., 2020; Yang et al., 2020).

013. Compatibility and inoperability: Different applications/systems work together in construction projects. Poor interoperability and connectivity adversely affect transferring and storing data (Li et al., 2019).

Market/ Industry level: According to Michael Porter's framework, the main dynamics of industries or sectors are buyers, suppliers, partners, and rivels (Johnson et al., 2008). Considering the construction industry's state, eight barriers to DLT implementation have been identified considering construction industry's condition.

M1. Network effects: Blockchain-based platforms need to engage sufficient users in viable business-tobusiness (B2B) and business-to-community (B2C) ecosystem (Mougayar and Buterin, 2016; Clohessy and Acton, 2019).

M2. Lack of customers' demand, interest, and tendency: DLT technology requires customers' interest and stakeholders' support to flourish in industries and markets (Barima, 2017; Saberi et al., 2018).

M3. Low usability: Low ease of use and high complexity of the DLT/ BCT adversely affect customers' journey experience and interaction with blockchain applications (Mougayar and Buterin, 2016; Helliar et al., 2020). 
M4. Limited access to lesson-learned and practices: Learning from previous mistakes and accessing the best practices of previous experience are necessary to reap DLT's benefits by industry players (Sawhney et al., 2020).

M5. Technical guidelines and standards: The construction sector needs globally agreed standards to run IT infrastructure for fewer overall risks, easier interoperability, data structure, and lower costs (Sawhney et al., 2020; McNamara and Sepasgozar, 2021).

M6. Lack of insurance mechanism: The inadequate insurance coverage to address the technical and business risks may prevent DLT adoption within the construction industry (Nawari and Ravindran, 2019).

M7. Technological state of the construction industry: The construction industry is not ready to embrace digital transformation due to traditional approaches and long-standing problems (Li et al., 2019; Sawhney et al., 2020).

M8. Market competition and heavily regulated segmentations: Some segmentations (e.g., infrastructure projects) are under pressure of market competition and heavy regulation due to their strategic place in society. These market forces might be barriers to adopt technological innovations (Kshetri, 2017; Saberi et al., 2018; Bürer et al., 2019).

Macro-environment level: Organizations and their projects are influenced by political, economic, social, technological, environmental, and legal (PESTEL) environments (Johnson et al., 2008). Nine barriers have been identified at the macro-environment level.

E1. Technology accessibility: Digital divide varies among societies, countries, and governments in the years of growth, adoption, and acceptance of technology (Saberi et al., 2018).

E2. Lack of government support: Governments and policymakers are not interested in emerging technologies in the particular blockchain. This technology acts independently without the control of governmental entities (Mougayar and Buterin, 2016).

E3. The volatility of cryptocurrency and fluctuating exchange rate: Cryptocurrencies are struggling with high volatility and fluctuations rate in the current years. It seems that underlying technologies of cryptocurrencies are not stable for use-cases and applications in the construction industry (Biswas and Gupta, 2019; Li et al., 2019).

E4. R\&D projects and higher training programs: With the arrival of construction 4.0, there is a high need for awareness-raising, investment in R\&D projects, and professional training programs (Sawhney et al., 2020).

E5. Lack of incentive and encouragement programs: One reason that dissuades industries from employing green technologies for sustainability is the lack of incentive schemes offered by governmental bodies (Saberi et al., 2018). 
E6. High energy consumption: Some consensus algorithms (i.e., Proof-of-Work) are not environmentally friendly due to high energy consumption and greenhouse gas emissions (Biswas and Gupta, 2019; Li et al., 2019).

E7. Legal issues: The construction industry heavily relies on laws and regulations for project execution and operation. Due to technology newness, there is a high need for new policies and technology laws (Li et al., 2019).

E8. Compliance requirements: Compliance requirements_ for Know Your Customer (KYC) and anti-money laundering (AML)_ are critical processes to verify the due-diligence of trading partners. The compliance requirement for onboarding stakeholders to the DLT platforms is accompanied by significant time, cost, and efforts (Hofmann et al., 2018).

E9. Taxation and reporting: Aside from recording transactions, this technology still requires taxation, reporting, and auditing (Mougayar and Buterin, 2016; Biswas and Gupta, 2019).

It is worthwhile to mention that the technical problems are excluded from discussion in this paper. Some of these challenges are i) immaturity of technology (Mougayar and Buterin 2016; Saberi et al. 2018), ii) vulnerability and confidentiality risks (Mougayar and Buterin 2016; Upadhyay 2020), iii) coding of the smart contract (Yang et al., 2020); Sheng et al. 2020), iv) theft of data, security issues, cybercrimes, system hacks, and hard forks (Li et al., 2019; Frizzo-barker et al. 2019), and finally v) misconception between DLT/blockchain and cryptocurrencies (Saberi et al., 2018).

\section{Ordinal Priority Approach (Opa)}

In practice, it is impossible to consider all types of drivers and even barriers simultaneously due to the time, budget, and resource constraints in the industries. Hence, the process of identifying, prioritizing, and taking response action on critical factors becomes imperative (Biswas and Gupta 2019; Kouhizadeh et al., 2021). In the blockchain literature, we found that scholars used a wide range of tools to analyze challenges, barriers, and critical factors. Table 1 presents state-of-the-art researches that use the following methodologies. 
Table 1

The list of methodologies used in previous studies for various objectives

Author/Year $\begin{aligned} & \begin{array}{l}\text { Research } \\ \text { methodology }\end{array} \\ & \text { Objective(s) }\end{aligned}$

(Biswas and DEMATEL

To rank ten barriers based on their prominence and relationships.

(Clohessy and

Acton, 2019)

(Ozdemir et al., 2020)

(Bag et al., 2020)

Ghode et al.

(2020)

Öztürk and

Yildizbaşi

(2020)

Sahebi et al.

(2020)

Yadav \& Singh

(2020)
A multiple-case study approach

IF-ANP
IF-DEMATEL and

To investigate the impact of organizational factors on blockchain adoption.

Exploring the relationships and interdependencies among barriers in humanitarian supply chain management (HSCM) based on blockchain benefits and weighting of criteria.

To analyze barriers to blockchain technology adoption in green supply chain management.

Fuzzy- DEMATEL

To rank the eight factors influencing the BCT adoption in SCM.

analysis (GRA)

Integrated MCDM:

Fuzzy AHP and

Fuzzy TOPSIS

Fuzzy Delphi and

Best-Worst method (BWM)

Principal

Component

Analysis (PCA)

and Fuzzy-

DEMATEL

Farooque et al. Fuzzy-DEMATEL (2020)

Erol et al.

(2020)

MCDM method combining fuzzy

AHP and fuzzy

TOPSIS

Orji et al.

Analytic Network

(2020)

Process (ANP)

Fuzzy Analytical Network Process (ANP)

Ozkan-Ozen et al. (2020)

DEMATEL

Kouhizadeh et al. (2021) approach

Mathivathanan TISM and et al. (2021) MICMAC
To prioritize 13 critical factors that overshadow blockchain adoption.

To assess 15 indicators affecting blockchain applications in industries.

To assess critical success factors in the blockchain-based sustainable SCM.

To analyze 18 barriers to blockchain technology adoption in SCM.

To analyze 14 barriers to blockchain adoption in the HSCM.

To prioritize 18 critical TOE factors (technology, organization, environment) that impact the BCT adoption in the freight logistics industry.

To prioritize 12 barriers that impede circular SCM in the industry 4.0 era.

To evaluate prominence and net effect values for factors that impact blockchain technology in the sustainable supply chain,

Using TISM and MICMAC to examines the interrelationships between nine barriers to blockchain technology in the business supply chain. 


\begin{tabular}{|lll|}
\hline Author/Year & $\begin{array}{l}\text { Research } \\
\text { methodology }\end{array}$ & Objective(s) \\
\hline $\begin{array}{l}\text { Vafadarnikjoo } \\
\text { et al. (2021) }\end{array}$ & N-AHP & $\begin{array}{l}\text { To analyze five barriers to blockchain technology adoption } \\
\text { in manufacturing supply chains. }\end{array}$ \\
\hline
\end{tabular}

Typically, decision-making approaches assess and prioritize several possible alternatives based on decision-makers' preferences. This paper needs an innovative solution to handle both 'sustainability' and 'digitalization' concepts by adopting DLT/BCT in the construction industry. The best method for this study is a novel decision-making approach that can evaluate the importance of barriers to DLT implementation based on sustainability attributes. Indeed, MADM methods can be employed to solve this type of problem. Ordinal Priority Approach (OPA) is a state-of-the-art technique proposed by (Ataei et al., 2020) to figure out MCDM problems through a linear mathematical model. OPA calculates the weights of alternatives, experts, and attributes simultaneously in a straightforward manner. The authors illustrate the superiority of the OPA method over similar decision-making techniques to date, as mentioned below:

1. The OPA calculates the ranks of alternatives (here barriers and challenges), weights of experts, and weights of criteria (here sustainability attributes) concurrently. Nevertheless, some decision-making techniques first calculate the weights of the attributes, then the rank of alternatives.

2. The OPA needs neither normalization methods nor the negative and positive ideal solutions. It can handle decision-making problems with incomplete data as well. When experts lack sufficient knowledge or relevant experience in the process of judgment, they are allowed to disregard some of the alternatives associated with a given attribute. This feature guarantees the accuracy of the final results and the efficiency of decision-making.

3. In most cases, aggregation methods cannot obtain reliable results because the outliers can remarkably decrease their efficiency. The OPA does not require averaging methods to collect experts' judgments in the group decision-making,

4. The OPA bypasses the decision-making matrix and does not use the pairwise comparison matrix of alternatives and attributes. Instead, the ordinal data regarding the attributes and alternatives are required.

In this context, Mahmoudi et al. (2021b) extended the OPA to Fuzzy OPA (OPA-F) for fuzzy linguistic information. It is used for uncertain conditions when experts are unsure about their opinions and suggest multiple ranks. Mahmoudi et al. (2020) presented a MCDM approach for the conditions when project managers are struggling with big data, and they need to make the optimal decision based on several attributes and alternatives. In this approach, principal component analysis (PCA) and k-means algorithm are used to cluster criteria and alternatives, respectively. After determining the optimal number of clusters, the integration approach of the fuzzy TOPSIS (TOPSIS-F) and OPA is used to solve the model. Mahmoudi et al. (2021a) employed Grey systems theory (GST) in the OPA to consider multiple ranks for criteria and alternatives. Grey OPA is usable in uncertainties without proposing a membership function or needs to a large sample. However, gathered data are ordinal, and we did not face these situations in the current 
study, and then, we have employed the original OPA. To explain the OPA steps, we need to know the variables, parameters, and sets first (Table 2).

Table 2. Sets, variables, and parameters in the OPA (Ataei et al., 2020)

\begin{tabular}{lc}
\hline Sets & \\
\hline $\mathbf{I}$ & Set of experts $\forall i \in \mathrm{I}$ \\
\hline $\mathbf{J}$ & Set of attributes $\forall j \in \mathrm{J}$ \\
\hline $\mathbf{K}$ & Set of alternatives $\forall k \in \mathrm{K}$ \\
\hline Indexes & Index of the experts $(1, \ldots, \boldsymbol{p})$ \\
\hline $\boldsymbol{i}$ & Index of preference of the attributes $(\mathbf{1}, \ldots, \boldsymbol{n})$ \\
\hline $\boldsymbol{j}$ & Index of the alternatives $(1, \ldots, \boldsymbol{m})$ \\
\hline $\boldsymbol{k}$ & \\
\hline $\mathbf{V}$ ariables & Objective function \\
\hline $\mathbf{Z}$ & Weight (importance) of $\boldsymbol{k}^{\text {th }}$ alternative based on $\boldsymbol{j}^{\text {th }}$ criterion by $\boldsymbol{i}^{\text {th }}$ expert at $\boldsymbol{r}^{\text {th }}$ rank \\
\hline $\boldsymbol{W}_{i j k}{ }^{r}$ & \\
\hline Parameters & The rank of expert $\boldsymbol{i}$ \\
\hline $\boldsymbol{i}$ & The rank of criterion $\boldsymbol{j}$ \\
\hline $\boldsymbol{j}$ & The rank of alternative $\boldsymbol{k}$ \\
\hline $\boldsymbol{r}$ &
\end{tabular}

The OPA is composed of several simple steps, which have been explained as follows:

Step 1. Determining the attributes: At this step, the attributes should be specified. In the current paper, we have already explored sustainability attributes in Section 2, Sub-section 2.1.

Step 2. Nominating and ranking the experts: Based on decision-making type (single or group), a scenario will be defined to specify and rate the experts based on indicators, such as academic qualification, professional experience, familiarity with the research topic, and so forth.

Step 3. Ranking the attributes: At this step, the attributes are prioritized through single/group decisionmaking. The expert(s) with insufficient knowledge or relevant experience can skip commenting on a particular attribute and exclude those attributes in the ranking.

Step 4. Ranking the alternatives in each attribute: At this step, expert(s) sort the alternative for each attribute.

Step 5. After solving Model (1), the optimal values for $W_{i j k}$ will be obtained.

$\operatorname{Max}$ Z

S.t: 
$Z \leq i\left(j\left(r\left(W_{i j k}^{r}-W_{i j k}^{r+1}\right)\right)\right) \quad \forall i, j, k$ and $r$

$Z \leq i j m W_{i j k}^{m} \quad \forall i, j$ and $k$

$\sum_{i=1}^{p} \sum_{j=1}^{n} \sum_{k=1}^{m} W_{i j k}=1$

$W_{i j k} \geq 0 \quad \forall i, j$ and $k$

where Z: Unrestricted in sign

Equation (2) can determine the weights of the barriers based on the optimal solutions by solving Model (1).

$W_{k}=\sum_{i=1}^{p} \sum_{j=1}^{n} W_{i j k} \quad \forall k$

To calculate the weights of the attributes, Equation (3) should be employed. It should be noted that tie ranks should be considered once.

$W_{j}=\sum_{i=1}^{p} \sum_{k=1}^{m} W_{i j k} \quad \forall j$

In the decision-making approach, the experts' weight can be obtained using Equation (4). It should be noted that tie ranks should be considered once.

$W_{i}=\sum_{j=1}^{n} \sum_{k=1}^{m} W_{i j k} \quad \forall i$

Considering this novelty and simplicity, we selected OPA in solving our MCDM problems.

\section{Implementing The Proposed Framework}

As shown in Fig. 1, we integrated the research framework with the OPA flowchart, presented by (Ataei et al., 2020), to show stages and deliverables of the current study.

According to the above flowchart, we first defined the research objective, and then we formulated research questions 1, 2, and 3 accordingly. Following that, we conducted keyword-based searches on the scientific databases: Web of Science (WoS), ScienceDirect, IEEE Xplore, John Wiley \& Sons, Inc., Springer, Emerald, and Taylor \& Francis. For this, we used the following keywords and terms: construction 4.0, construction industry, distributed ledger technology (DLT), blockchain, smart contract, challenges, and barriers. The 
literature search resulted in roughly 250 publications. Then, inclusion and exclusion criteria were applied to context, abstracts, and conclusions to select appropriate studies. In sub-Sect. 2.1, we based our foundation on identifying sustainability attributes. Following that, in sub-Sect. 2.2, we identified the barriers to DLT implementation.

Due to limitations caused by the global pandemic (COVID-19), we arranged multiple virtual meetings with experts to discuss factors. We established this process a couple of times to compile experts' feedbacks and finalize the identified factors. To assess the applicability of factors in the construction industry, we considered real-case studies (Sect. 5) in a group decision-making approach. Then, we followed the OPA steps to figure out our decision problem. OPA provided us with the experts' weight, the weight of attributes, and alternatives ranks.

\section{Case Study And Discussion}

Given the literature review section, 30 criteria and 41 alternatives are considered in our decision problem. For more clarification, the structure of the decision problem is illustrated below (Fig. 2).

According to the decision problem, a questionnaire was designed in three parts (Appendix A). To assess barriers in the construction industry, we invited 15 high-ranked executives in the construction industry willing to adopt DLT into their business and firms. However, we decided to consider the data of six respondents after an initial review of their competencies and responses. More details about criteria to select cases are presented in (Appendix B). Then, we followed Step 2 of OPA to define a scenario based on experts' priority and order:

\section{Scenario: Expert $4>$ Expert $1>$ Expert $6>$ Expert $2>$ Expert $5=$ Expert 3}

In the last step, OPA is solved to obtain 'weight of sustainability attributes' and 'ranking the barriers.'

- Weight of sustainability attributes: In Step 3 of OPA, experts were asked to determine and sort 30 sustainability attributes in order. After solving OPA in Step 5, the results are illustrated in Fig. 3_for the project, organization, market, and macro-environment level. The results show that the implementation of DLT can result in social sustainability mostly.

The outputs of the OPA model highlight that the top three attributes in social sustainability are SC10, SC11, SC12; The top attribute in economic sustainability is EC8; The top attribute in environmental sustainability is EN2; The top attribute in project sustainability is PS2. This implies that removing obstacles, regardless of what level they are, can primarily result in sustainability in the factors above.

DLT/BCT can play a dominant role in social sustainability. First, it improves 'SC10. supply chain management and procurement.' This technology enables effective procurement management and (semi)automated sourcing of products/services with high traceability, visibility, and accuracy. Second, it enhances 'SC11. transparency, anti-corruption, and anti-counterfeiting.' Providing transparent communication and fully auditable information eliminates the risks of corruption and fraudulent claims. 
Third, this technology promises to 'SC12. fair operation and honest competition.' With the help of DLT, it is possible to monitor participants' behavior in a P2P network to ensure that the nodes do not engage in anti-competitive behavior. Or, suppliers are selected based on fair competition and key performance indicators.

DLT can contribute to 'EC8. circular economy' significantly. Companies can harvest technologies like DLT/ Blockchain for providing services/products based on circular economy principles (reusing resources, reducing waste, recycling materials, and minimizing carbon footprints) in a transparent and traceable way. DLT's role in 'EN2. digital communication' is also notable. DLT provides collaborative synergy and digital communication through distributed networks. Last but not least, it takes a while for emerging technologies to enter the scene and presents new applications for construction projects. Accordingly, DLT has not proved its potentials on 'PS1. product impacts' and 'PS2. process impacts.'

- Ranking the barriers at the project level: In Step 4 of OPA, experts were asked to rank 11 barriers for each sustainability attributes at the project level. After solving OPA in Step 5, the result is illustrated in Fig. 4.

As shown in Fig. 4, 'P5. infrastructure for data management' is the highest-ranked alternative with a weight of (0.10228). The integration of DLT and other technologies provides factual and real-time data on a large scale that can be used in the executive dashboard and data-driven decision-making. This technology requires infrastructure for data management, such as global positioning system (GPS) technology, protected collaborators, and sensors on project sites with sustainable connection and minimum shutdown. Both software and hardware should be resistant to any malfunctions and manipulation to capture, cluster, and store data throughout the project life cycle for future use (Zhang et al., 2020). The next influencing alternative is ' $P 1$. abuse and fraud' with a weight of (0.09884). Shortly after DLT/BCT penetration in projects, users will identify system bugs. As a result, scams and fraud are not entirely eradicated with this technology. 'P2. manual processes and traditional practices' take third place with a weight of (0.09624). Automation may challenge traditional tools and techniques controlled by closed ledgers. In this case, companies may prefer commonly-used practices like enterprise resource planning (ERP) due to the enormous effort and investment in implementing (Sheng et al., 2020) and trust in their efficiency (Wang et al., 2019).

'P4. Authenticity, consistency, and legitimacy of data' is the fourth important barrier that reminds the 'garbage in, garbage out' concept. Poor data quality and corrupted inputs (Schmidt and Wagner, 2019), and dispersal of inaccurate information (Saberi et al., 2018) will result in network failure. Information redundancy may also adversely impact the systems' performance (Sheng et al., 2020) while transferring and storing large-size files (e.g., BIM documents). DLT/BCT requires sensitive data protection (Yang et al., 2020), information disclosure policy (Farooque et al., 2020), and consistent data for the execution of smart contracts ( $\mathrm{Li}$ et al., 2019). With a slight difference, 'P9. scalability problems' ranks fifth. It takes seconds to settle transactions, which is a long time for construction projects where timing matters. This challenge may disrupt the performance of the internet of things (IoT), where a massive amount of data exchange continuously with DLT platforms (Tapscott and Tapscott, 2016). Indeed, intelligent algorithms 
and high computational power for safe and secure transaction settlement are highly required ( $\mathrm{V}$. Chang et al., 2020). 'P3. irreversibility and immutability of the process' comes next, in the sixth rank. DLT/BCT has been struggling with long-lasting issues that may discourage stakeholders from using this technology which is the immutability of automated tasks and smart contracts (Saberi et al., 2018; Sheng et al., 2020) and the lack of controlling mechanisms for automated tasks (Expert's idea).

P8, P11, P10, and P7 are alternatives with moderate importance on sustainability. Finally, 'P6. contractual standards' is considered the least influential barrier with the lowest weight of (0.08134). According to the experts, construction projects need standard contractual models when technologies play a dominant role. This requirement is about agreement provisions, responsibilities of automated actions, risk distribution, change management, the parties' right to issue a claim, and protocols to resolve disputes. It seems that experts did not find any association between this challenge and sustainability attributes.

- Ranking the barriers at the organizational level: In step 4 of OPA, experts were asked to assess 13 barriers and sort them in each sustainability criterion at the organizational level. After solving OPA in Step 5 , the result is illustrated in Fig. 5.

As shown in Fig. 5, 011, 013, and 010 are the three top-ranked barriers based on the obtained weights. '011. lack of advanced applications and archetypes' is the most challenging, with a score of (0.09395). However, the Java Virtual Machine (JVM) enables programmers to develop various distributed applications (DApps), it seems that running applications still need a vibrant ecosystem. Moreover, the number of successful archetypes is not remarkable when the underlying technology is nascent (Mougayar and Buterin, 2016). '013. compatibility and inoperability' has a second position with a value of (0.08964). A decentralized network requires a complete series of digital levers (e.g., oracles, API solutions, and standardization) and data processing technologies (e.g., BIM, loT, and Al) to operate efficiently (Wang et al., 2019; Y. Chang et al., 2020). Since these technologies are developed by various manufacturers and operate under specified protocols, AEC entities will witness low compatibility among existing systems. '010. system robustness and full technology stack' attained the third-highest rank with a weight of (0.08868). Network stability, server capacity, internet bandwidth, continual connectivity, and trustworthy systems are required for data exchange with transparency, stability, and security without intermediaries (Yadav and Singh, 2020). Lack of minimum technological requirements will result in data loss, break down the supply chain, and poor provenance of goods/services.

'09. legacy systems' places as the fourth priority. Organizations are trying to address seamless integration of blockchain with available IT infrastructure (Wang et al., 2019) by upgrading existing legacy systems or replacing some pieces (Tapscott and Tapscott 2016; Saberi et al., 2018). '012. wide rollout and large-scale technology adoption' comes in the fifth position. Organizational readiness, training staff, robust technology stack, and selecting appropriate DLT/blockchain systems are the requirements for realscale adoption (Yang et al., 2020). '08. scarcity in multidisciplinary experts and developers' ranks in sixth place in this group. Construction 4.0 is on the way, and organizations need well-trained teams of qualified individuals to address this new market (V. Chang et al. 2020; Lohmer and Lasch 2020). Organizations 
also can alleviate this problem by outsourcing the implementation of DLT adoption to qualified third-party consultants (Chong and Diamantopoulos, 2020) or technology providers (Farooque et al., 2020).

$03,07,06,02,01$ comes in seventh, eighth, ninth, 10th, 11th rank as moderate-important barriers. ' 04 . financial constraints and cost of adoption' and '05. uncertain return of investment (ROI)' are the least challenging barriers with the weights of $(0.06443)$ and $(0.06202)$, respectively. Although DLTs are free open-sourced platforms, top managers need a vivid picture of the cost breakdown structure (CBS) to allocate enough financial resources on platform development, operation, and maintenance (Esmaeilian et al. 2020; V. Chang et al. 2020; Zhang et al. 2020). Nevertheless, prospect consequences, earned value, the return of investment (ROI), and sustainability contributions might be covered until the wide-scale deployment of DLT/blockchain (Bai et al. 2020; Y. Chang et al. 2020). It can be perceived that experts did not find any association between this challenge and sustainability attributes.

- Ranking the barriers at the market level: In step 4 of OPA, experts were asked to sort eight barriers for each criterion, At the third layer of the construction ecosystem. After solving OPA in Step 5, the result is illustrated in Fig. 6.

As shown in Fig. 6, M2, M3, and M1 are the top-rated barriers with the weights of (0.17518), (0.15177), and (0.13919), respectively. According to 'M2,' DLT/BCT adoption may not have stakeholders' support and interest due to insufficient knowledge around underlying technology. V. Chang et al. (2020) asserted that DLT adoption is a step-by-step process for high-quality products/services realized by communities' support. 'M3. low usability' comes in the second rank. The current DApps and software still need to improve customers' journey and user interface (UI). 'M1. network effects' comes in the third rank. Distributed applications (DApps) need critical mass users for better performance in the business environment (Wang et al., 2019).

In this order, 'M7. technological state of the construction industry' comes in fourth place. In the digital transformation era, the construction industry may face skepticism, resistance, or ignorance toward technologies (Sawhney et al., 2020). Shifting from legacy systems to the distributed ledger is likely costly and accompanied by delays or even failures, particularly in the initial years for this industry. 'M8. market competition and heavily regulated segmentations' comes in fifth place. Infrastructure and industrial construction projects have been in the government spotlight due to their pivotal role in producing strategic products, such as water, energy, electricity, and telecommunications. These segmentations are highly regulated, with no freedom for technology penetration like DLT/BCT, since the governing bodies set strict rules to secure the industries, market players, and customers (experts' idea).

The sixth sub-barrier is 'M5. Technical guidelines and standards'. DLT/BCT implementation is slowed down by the absence of the technical guidelines, standards, and detailed roadmap for AEC entities. Typically, standards are adopted from other industries or generated within the international collaboration, standard institutes, cross-industry strategic partnerships, or professional syndicates. In this particular case, the synergy between sectors or companies can provide solutions to technical challenges and make reference points more available (Bürer et al., 2019; Lu et al., 2019).

Page 18/32 
Finally, M4 and M6 are the least influencing alternatives in the implementation of DLT. Considering 'M4. limited access to lesson-learned and practices', not all technology firms have necessarily achieved fruitful results. They are often unwilling to share the lean knowledge and first-hand experiences gained through failure or success. Moreover, innovative concepts are isolated within industries, large-sized companies, and technology giants (Lohmer and Lasch, 2020). Lastly, 'M6. lack of insurance mechanism' comes as the least value in the order. Insurance is an undeniable part of the construction industry to protect projects from various risks and address claims based on factual data (Nawari and Ravindran, 2019). One reason that can dissuade organizations from using emerging technologies is the low insurance coverage to address cyberattacks' risks in the projects. It can be perceived that experts did not find any association between this challenge and sustainability attributes.

- Ranking the barriers at the PESTEL-Macro Environment level: We identified nine barriers to DLT adoption at the macro-level of the construction ecosystem. In step 4 of OPA, the experts were asked to assess nine barriers and sort them in each sustainability criterion. After solving OPA in Step 5, the result is illustrated in Fig. 7.

As shown in Fig. 7, the top three barriers are E9, E5, E8, with the weights $(0.14280),(0.12674)$, and (0.11555), respectively. According to 'E9. taxation and reporting', this technology still requires development in capabilities like taxation, reporting, and auditing (Mougayar and Buterin, 2016). 'E5. lack of incentive and encouragement programs' comes in the second rank. Until recently, the construction industry has not demonstrated excellent performance in adopting corporate social responsibility (CSR) and sustainability principles. Lack of incentive/penalty system, and limited resources and budget are some factors that impede implementing technology for sustainability (Zhang et al., 2020). 'E8. Compliance requirements' is the third most crucial barrier. Either compliance or non-compliance are overhead costs that squeeze profit margins. Compliance also keeps a business updated on related regulations and policies, with examples such as ISO, ASME, OSHA in the construction industry, NEC3 and NEC4 for smart contracts (Penzes, 2018).

E3, E1, E4, E2 comes in fourth, fifth, sixth, and seventh barriers with moderate importance. The last two less challenging barriers in the implementation of DLT/BCT are E6 and E7. 'E6. high energy consumption,' in an eighth rank, discusses high energy consumption by DLT for computational power. Among consensus algorithm, the 'proof-of-work' model consumes high energy for the hashing process and solving the cryptographic puzzles, which seem to be not economical, ecological, and environmental friendly (Mougayar and Buterin, 2016), and organizations need sufficient electrical supplies for adopting blockchain (V. Chang et al., 2020). 'E7. legal issues' attained the last position in this group. DLT/BCT is independent of any central controls, and policymakers seek a way to regulate this technology to observe autonomous agents. On the other side, AEC entities need laws and regulations for project execution. Hence, industries like the construction industry need governmental policies and transparent regulatory systems regarding emerging technologies (O'Dair, 2018).

\section{Conclusion}


Distributed ledger technology, often called blockchain, is among the most disruptive forces that have revolutionized project delivery, business models, and industries. The construction industry has no way to embrace technological breakthroughs for higher efficiency, productivity, smarter products, and services. A recent literature review shows that several barriers and challenges are facing the construction industry while adopting DLT. In this regard, we base the study's foundation on identifying barriers and prioritizing them based on the sustainable development approach. To achieve the research objectives, we identified several barriers and sustainability attributes from the literature. To assess the applicability of factors in the AEC sector, we targeted real-world case studies and gathered data from experts specialized in construction projects, sustainability, and emerging technologies.

This study's contributions are employing the OPA and solving model for ranking 41 barriers, weighing 30 sustainability attributes based on six qualified experts' opinions. This method allows experts' priority scenario to solve MCDM problems. The findings revealed that " $\mathrm{P} 5$. infrastructure for data management" is the top-ranked barrier at the project level. At the organization level, "011. lack of advanced applications and archetypes" is the most challenging alternative. At the market level, it can be perceived that "M2. lack of customers' demand, interest, and tendency" is the most critical barrier. And finally, in the top layer of the AEC ecosystem, DLT requires improvement in "E9. taxation and reporting." Meanwhile, the obtained results show that addressing the high-ranked barriers can result in social sustainability in the most, then economic and environmental sustainability, and the least impact on project sustainability. In other words, alleviating challenges can result in "SC10. supply chain management and procurement," "SC11. transparency, anti-corruption, and anti-counterfeiting," "SC12. fair operation and honest competition."

Last but not least, we encountered some limitations within this study. The global pandemic (COVID19) overshadowed our virtual meetings to gather comments about alternatives and sustainability attributes. Second, to collect the data based on the sustainability approach, finding qualified and selecting experts took a long time. Experts should be chosen carefully based on competency requirements, including academic qualification, knowledge in construction, general understanding of DLT/blockchain, and relevant experience. In future studies, the OPA method can be utilized for making the optimal decision toward identified barriers and take response action accordingly. In a broader sense, more research is needed to provide a detailed decision framework using the OPA method to help the project team and organization executives to implement DLT technology based on their preference and needs of real-world situations.

\section{Declarations}

- Ethics approval and consent to participate: The need for approval was waived.

- Consent for publication: Not applicable

- Availability of data and materials: The data that support the findings of this study are available on request from the corresponding author.

- Competing interests: The authors declare that they have no competing interests. 
- Funding: This study was supported by the National Natural Science Foundation of China under grant no. NSFC-71771052.

- Authors' contributions: Mahsa Sadeghi: Conceptualization, software, and writing - original draft. Amin Mahmoudi: Conceptualization, methodology, software, writing-original draft, review and editing. Xiaopeng Deng: Validation, writing - review and editing, supervision.

- Acknowledgements: Not applicable

- Authors' information (optional): Not applicable

\section{References}

1. Ataei Y, Mahmoudi A, Feylizadeh MR, Li DF (2020) Ordinal Priority Approach (OPA) in Multiple Attribute Decision-Making. Appl Soft Comput J 86:105893.

https://doi.org/10.1016/j.asoc.2019.105893

2. Bag S, Viktorovich DA, Sahu A, Kumar S, Kumar A (2020) Barriers to adoption of blockchain technology in green supply chain management. J Glob Oper Strateg Sourc. https://doi.org/10.1108/JGOSS-06-2020-0027

3. Bai C, Dallasega P, Orzes G, Sarkis J (2020) Industry 4. 0 technologies assessment : A sustainability perspective. Int J Prod Econ 229:107776. https://doi.org/10.1016/j.ijpe.2020.107776

4. Barima $O$ (2017) Leveraging the Blockchain Technology to Improve Construction Value Delivery: The Opportunities, Benefits and Challenges. In: Hall, Kimberly (eds) Construction Projects Improvement Strategies, Quality Management and Potential Challenges. Nova Science Publishers, Inc., New York, p 194

5. Biswas B, Gupta R (2019) Analysis of barriers to implement blockchain in industry and service sectors. Comput Ind Eng 136:225-241. https://doi.org/10.1016/j.cie.2019.07.005

6. Bodkhe U, Tanwar S, Parekh K, Khanpara P, Tyagi S, Kumar N, Alazab M (2020) Blockchain for Industry 4.0: A comprehensive review. IEEE Access 8:79764-79800. https://doi.org/10.1109/ACCESS.2020.2988579

7. Bürer MJ, de Lapparent M, Pallotta V, Capezzali M, Carpita M (2019) Use cases for Blockchain in the Energy Industry Opportunities of emerging business models and related risks. Comput Ind Eng 137:106002. https://doi.org/10.1016/j.cie.2019.106002

8. Chang V, Baudier P, Zhang H, Xu Q, Zhang J, Arami M (2020) How Blockchain can impact financial services - The overview, challenges and recommendations from expert interviewees. Technol Forecast Soc Change 158:120166. https://doi.org/10.1016/j.techfore.2020.120166

9. Chang Y, lakovou E, Shi W (2020) Blockchain in global supply chains and cross border trade: a critical synthesis of the state-of-the-art, challenges and opportunities. Int J Prod Res 58:2082-2099. https://doi.org/10.1080/00207543.2019.1651946

10. Chong HY, Diamantopoulos A (2020) Integrating advanced technologies to uphold security of payment: Data flow diagram. Autom Constr 114:103158. 
https://doi.org/10.1016/j.autcon.2020.103158

11. Clohessy $T$, Acton $T$ (2019) Investigating the influence of organizational factors on blockchain adoption: An innovation theory perspective. Ind Manag Data Syst 119:1457-1491. https://doi.org/10.1108/IMDS-08-2018-0365

12. De Giovanni P (2020) Blockchain and smart contracts in supply chain management: A game theoretic model. Int J Prod Econ 228:107855. https://doi.org/10.1016/j.ijpe.2020.107855

13. Erol I, Ar IM, Ozdemir Al, Peker I, Asgary A, Medeni IT, Medeni T (2020) Assessing the feasibility of blockchain technology in industries: evidence from Turkey. J Enterp Inf Manag. https://doi.org/10.1108/JEIM-09-2019-0309

14. Esmaeilian B, Sarkis J, Lewis K, Behdad S (2020) Blockchain for the future of sustainable supply chain management in Industry 4.0. Resour. Conserv Recycl 163:105064. https://doi.org/10.1016/j.resconrec.2020.105064

15. Farooque M, Jain V, Zhang A, Li Z (2020) Fuzzy DEMATEL analysis of barriers to Blockchain-based life cycle assessment in China. Comput Ind Eng 147:106684. https://doi.org/10.1016/j.cie.2020.106684

16. Fosso Wamba S, Queiroz MM, Trinchera L (2020) Dynamics between blockchain adoption determinants and supply chain performance: An empirical investigation. Int J Prod Econ 229:107791. https://doi.org/10.1016/j.ijpe.2020.107791

17. Frizzo-barker J, Chow-white PA, Adams PR, Mentanko J, Ha D, Green S (2019) Blockchain as a disruptive technology for business: A systematic review. Int J Inf Manage 0-1. https://doi.org/10.1016/j.jinfomgt.2019.10.014

18. Ghode D, Yadav V, Jain R, Soni G (2020) Adoption of blockchain in supply chain: an analysis of influencing factors. J Enterp Inf Manag 33:437-456. https://doi.org/10.1108/JEIM-07-2019-0186

19. Global GPM (2019) The GPM P5 ${ }^{\text {TM }}$ Standard for Sustainability in Project Management (Version 2.0)

20. Helliar CV, Crawford L, Rocca L, Teodori C, Veneziani M (2020) Permissionless and permissioned blockchain diffusion. Int J Inf Manage 54:102136. https://doi.org/10.1016/j.ijinfomgt.2020.102136

21. Hilton U, Asmussen J, Mølbjerg RW, Knudsen U, Søgaard JS, Andersen LN, Schannong S (2019) Business blockchains. Denmark

22. Hofmann E, Strewe UM, Bosia N (2018) Supply Chain Finance and Blockchain Technology, The Case of Reverse Securitisation, Springer. Springer, Cham. https://doi.org/10.1007/978-3-319-62371-9_5

23. Hunhevicz JJ, Hall DM (2020) Do you need a blockchain in construction? Use case categories and decision framework for DLT design options. Adv Eng Informatics 45. https://doi.org/10.1016/j.aei.2020.101094

24. Janssen M, Weerakkody V, Ismagilova E, Sivarajah U, Irani Z (2020) A framework for analysing blockchain technology adoption: Integrating institutional, market and technical factors. Int $\mathrm{J}$ Inf Manage 50:302-309. https://doi.org/10.1016/j.ijinfomgt.2019.08.012 
25. Johnson G, Scholes K, Whittington R (2008) Exploring Corporate Strategy: Strategic Formulation and Implementation: Text and Cases. Financial Times Prentice Hall

26. Kouhizadeh M, Saberi S, Sarkis J (2021) Blockchain technology and the sustainable supply chain: Theoretically exploring adoption barriers. Int J Prod Econ 231:107831. https://doi.org/10.1016/j.ijpe.2020.107831

27. Kshetri N (2017) Will blockchain emerge as a tool to break the poverty chain in the Global South? Third World Q 38:1710-1732. https://doi.org/10.1080/01436597.2017.1298438

28. Kumar P, Singh RK, Kumar V (2021) Managing supply chains for sustainable operations in the era of industry 4.0 and circular economy: Analysis of barriers. Resour Conserv Recycl 164:105215. https://doi.org/10.1016/j.resconrec.2020.105215

29. Leng J, Ruan G, Jiang P, Xu K, Liu Q, Zhou X, Liu C (2020) Blockchain-empowered sustainable manufacturing and product lifecycle management in industry 4.0: A survey. Renew Sustain Energy Rev 132:110112. https://doi.org/10.1016/j.rser.2020.110112

30. Li J, Greenwood D, Kassem M (2019) Blockchain in the built environment and construction industry: A systematic review, conceptual models and practical use cases. Autom Constr 102:288-307. https://doi.org/10.1016/j.autcon.2019.02.005

31. Lohmer J, Lasch R (2020) Blockchain in operations management and manufacturing: Potential and barriers. Comput Ind Eng 149:106789. https://doi.org/10.1016/j.cie.2020.106789

32. Lu H, Guo L, Azimi M, Huang K (2019) Oil and Gas 4.0 era: A systematic review and outlook. Comput Ind 111:68-90. https://doi.org/10.1016/j.compind.2019.06.007

33. Mahmoudi A, Deng X, Javed SA, Yuan J (2020) Large-scale multiple criteria decision-making with missing values: project selection through TOPSIS-OPA. J Ambient Intell Humaniz Comput. https://doi.org/10.1007/s12652-020-02649-w

34. Mahmoudi A, Deng X, Javed SA, Zhang N (2021a) Sustainable Supplier Selection in Megaprojects: Grey Ordinal Priority Approach. Bus Strateg Environ 30:318-339. https://doi.org/10.1002/bse.2623

35. Mahmoudi A, Javed SA, Mardani A (2021b) Gresilient supplier selection through Fuzzy Ordinal Priority Approach: decision-making in post-COVID era. Oper Manag Res. https://doi.org/10.1007/s12063-021-00178-z

36. Marsal-Llacuna ML (2018) Future living framework: Is blockchain the next enabling network? Technol. Forecast Soc Change 128:226-234. https://doi.org/10.1016/j.techfore.2017.12.005

37. Mathivathanan D, Mathiyazhagan K, Rana NP, Khorana S, Dwivedi YK (2021) Barriers to the adoption of blockchain technology in business supply chains: a total interpretive structural modelling (TISM) approach. Int J Prod Res 1-22. https://doi.org/10.1080/00207543.2020.1868597

38. McNamara AJ, Sepasgozar SME (2021) Intelligent contract adoption in the construction industry: Concept development. Autom Constr 122:103452. https://doi.org/10.1016/j.autcon.2020.103452

39. Mougayar W, Buterin V (2016) The Business Blockchain_Promise, Practice, and Application of the Next Internet Technology-Wiley (2016). John Wiley \& Sons, Inc 
40. Nakamoto S (2008) Bitcoin: A Peer-to-Peer Electronic Cash System

41. Nandi S, Sarkis J, Hervani AA, Helms MM (2020) Redesigning Supply Chains using BlockchainEnabled Circular Economy and COVID-19 Experiences. Sustain Prod Consum. https://doi.org/10.1016/j.spc.2020.10.019

42. Nawari NO, Ravindran S (2019) Blockchain and the built environment: Potentials and limitations. J Build Eng 25:100832. https://doi.org/10.1016/j.jobe.2019.100832

43. O’Dair M (2018) Distributed creativity: How blockchain technology will transform the creative economy. Palgrave Macmillan, Springer Nature Switzerland AG. https://doi.org/10.1007/978-3-03000190-2

44. Orji IJ, Kusi-Sarpong S, Huang S, Vazquez-Brust D (2020) Evaluating the factors that influence blockchain adoption in the freight logistics industry. Transp Res Part E Logist Transp Rev 141:102025. https://doi.org/10.1016/j.tre.2020.102025

45. Ozdemir Al, Erol I, Ar IM, Peker I, Asgary A, Medeni TD, Medeni IT (2020) The role of blockchain in reducing the impact of barriers to humanitarian supply chain management. Int J Logist Manag. https://doi.org/10.1108/IJLM-01-2020-0058

46. Ozkan-Ozen YD, Kazancoglu Y, Kumar Mangla S (2020) Synchronized Barriers for Circular Supply Chains in Industry 3.5/Industry 4.0 Transition for Sustainable Resource Management. Resour Conserv Recycl 161:104986. https://doi.org/10.1016/j.resconrec.2020.104986

47. Öztürk C, Yildizbaşi A (2020) Barriers to implementation of blockchain into supply chain management using an integrated multi-criteria decision-making method: a numerical example. Soft Comput 24:14771-14789. https://doi.org/10.1007/s00500-020-04831-w

48. Penzes B (2018) Blockchain Technology in the Construction Industry: Digital Transformation for High Productivity, ice.org.uk. London

49. Petri I, Barati M, Rezgui Y, Rana OF (2020) Blockchain for energy sharing and trading in distributed prosumer communities. Comput Ind 123:103282. https://doi.org/10.1016/j.compind.2020.103282

50. Saberi S, Kouhizadeh M, Sarkis J, Shen L (2018) Blockchain technology and its relationships to sustainable supply chain management. Int J Prod Res 57:2117-2135. https://doi.org/10.1080/00207543.2018.1533261

51. Sahebi IG, Masoomi B, Ghorbani S (2020) Expert oriented approach for analyzing the blockchain adoption barriers in humanitarian supply chain. Technol Soc 63:101427. https://doi.org/10.1016/j.techsoc.2020.101427

52. Sawhney A, Riley M, Irizarry J (2020) CONSTRUCTION 4.0: An Innovation Platform for the Built Environment. Routledge, Taylor \& Francis Group, London, United Kingdom. https://doi.org/https://doi.org/10.1201/9780429398100

53. Schmidt CG, Wagner SM (2019) Blockchain and supply chain relations: A transaction cost theory perspective. J Purch Supply Manag 25. https://doi.org/10.1016/j.pursup.2019.100552

54. Sheng D, Ding L, Zhong B, Love PED, Luo H, Chen J (2020) Construction quality information management with blockchains. Autom Constr 120:103373. 
https://doi.org/10.1016/j.autcon.2020.103373

55. Silvius G, Schipper R, Köhler A, Brink J, van den, Planko J (2012) Sustainability in project management. Routledge, Taylor \& Francis Group, London, United Kingdom. https://doi.org/https://doi.org/10.4324/9781315241944

56. Tapscott D, Tapscott A (2016) Blockchain Revolution: How the Technology Behind Bitcoin Is Changing Money, Business, and the World. Penguin Random House LLC, New York

57. Upadhyay N (2020) Demystifying blockchain: A critical analysis of challenges, applications and opportunities. Int J Inf Manage 54:102120. https://doi.org/10.1016/j.ijinfomgt.2020.102120

58. Vafadarnikjoo A, Badri Ahmadi H, Liou JJH, Botelho T, Chalvatzis K (2021) Analyzing blockchain adoption barriers in manufacturing supply chains by the neutrosophic analytic hierarchy process. Ann Oper Res 1-28. https://doi.org/10.1007/s10479-021-04048-6

59. Wamba SF, Queiroz MM (2020) Blockchain in the operations and supply chain management: Benefits, challenges and future research opportunities. Int $\mathrm{J}$ Inf Manage. https://doi.org/10.1016/j.ijinfomgt.2019.102064

60. Wang Y, Singgih M, Wang J, Rit M (2019) Making sense of blockchain technology: How will it transform supply chains? Int J Prod Econ 211:221-236. https://doi.org/10.1016/j.ijpe.2019.02.002

61. WEF (2016) Shaping the Future of Construction A Breakthrough in Mindset and Technology. Geneva, Switzerland

62. Yadav S, Singh SP (2020) Blockchain critical success factors for sustainable supply chain. Resour Conserv Recycl 152:104505. https://doi.org/10.1016/j.resconrec.2019.104505

63. Yang R, Wakefield R, Lyu S, Jayasuriya S, Han F, Yi X, Yang X, Amarasinghe G, Chen S (2020) Public and private blockchain in construction business process and information integration. Autom Constr 118:103276. https://doi.org/10.1016/j.autcon.2020.103276

64. Zhang A, Zhong RY, Farooque M, Kang K, Venkatesh VG (2020) Blockchain-based life cycle assessment: An implementation framework and system architecture. Resour Conserv Recycl 152:104512. https://doi.org/10.1016/j.resconrec.2019.104512

\section{Figures}




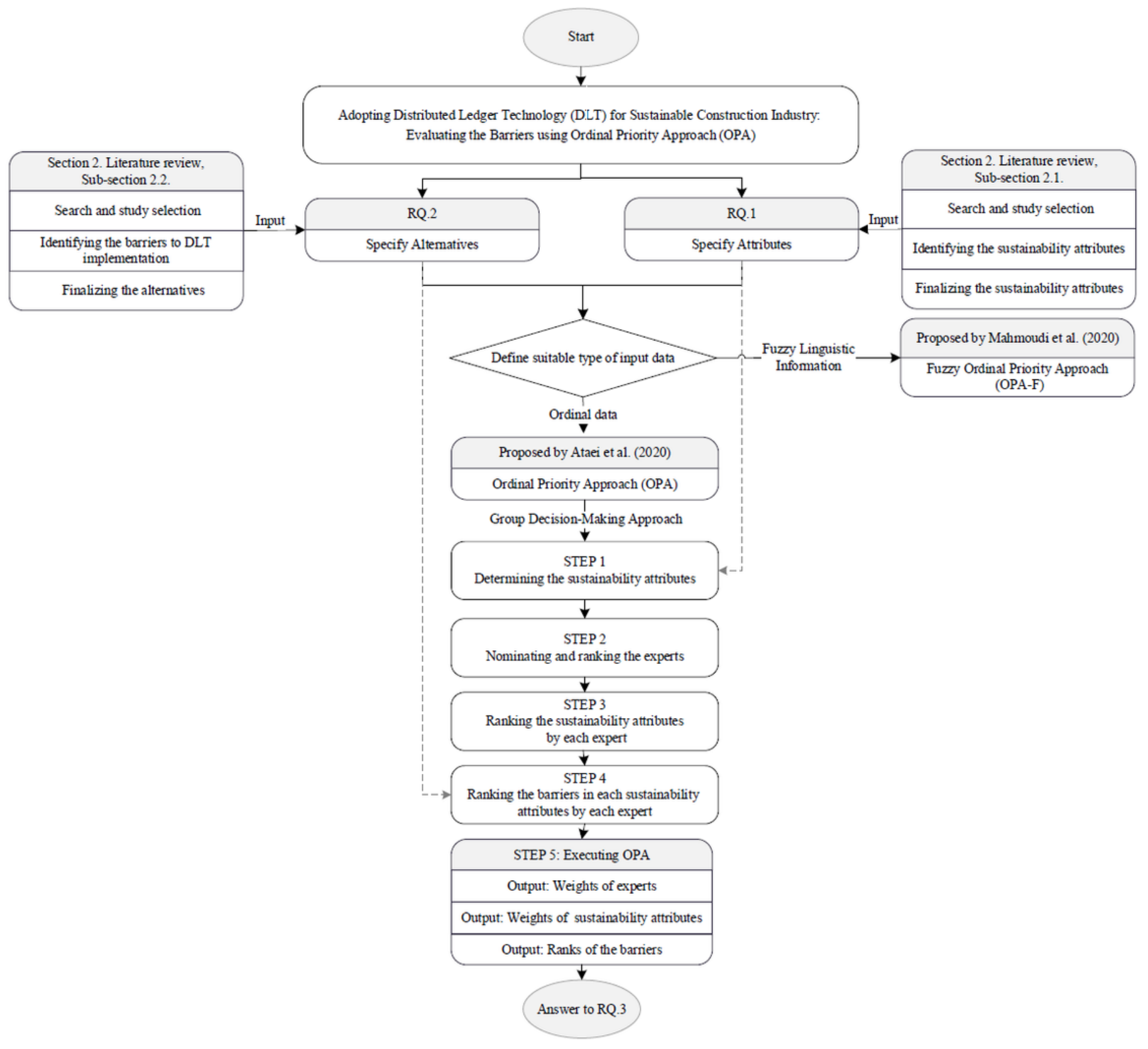

\section{Figure 1}

Flowchart of the stages for our research study 


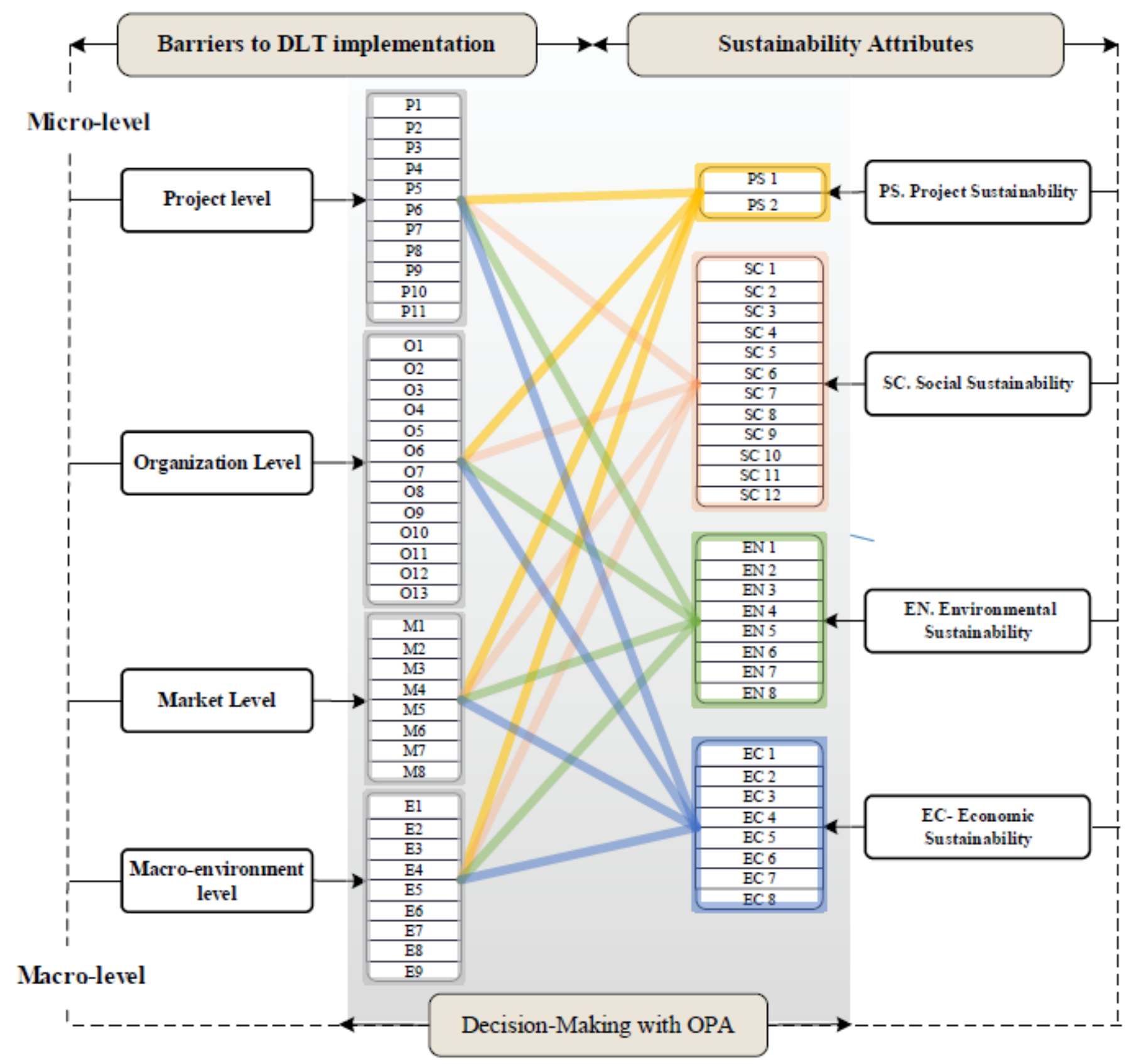

Figure 2

The structure of the decision problem 


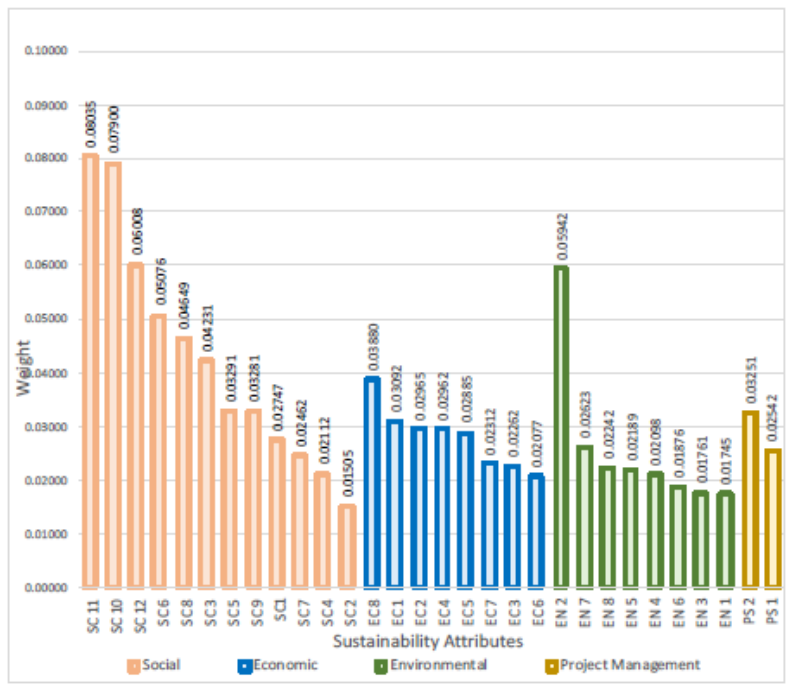

a: Weight of sustainability attributes for the project level

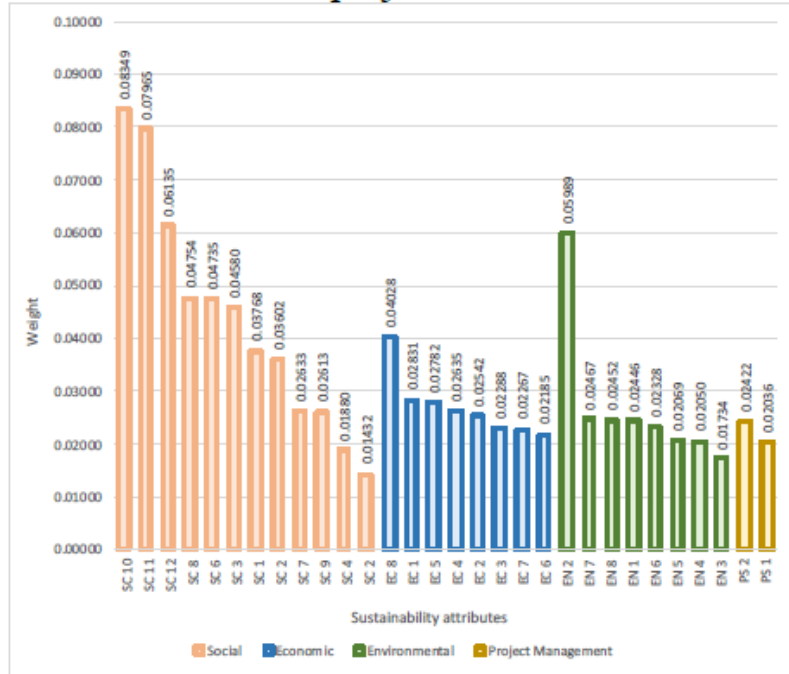

c: Weight of sustainability attributes for the market level

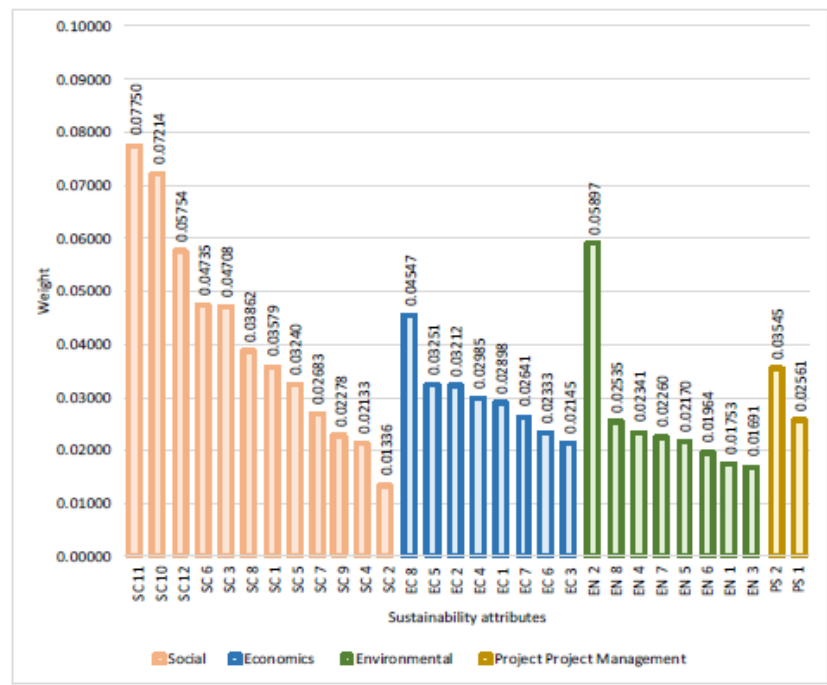

b: Weight of sustainability attributes for the organization level

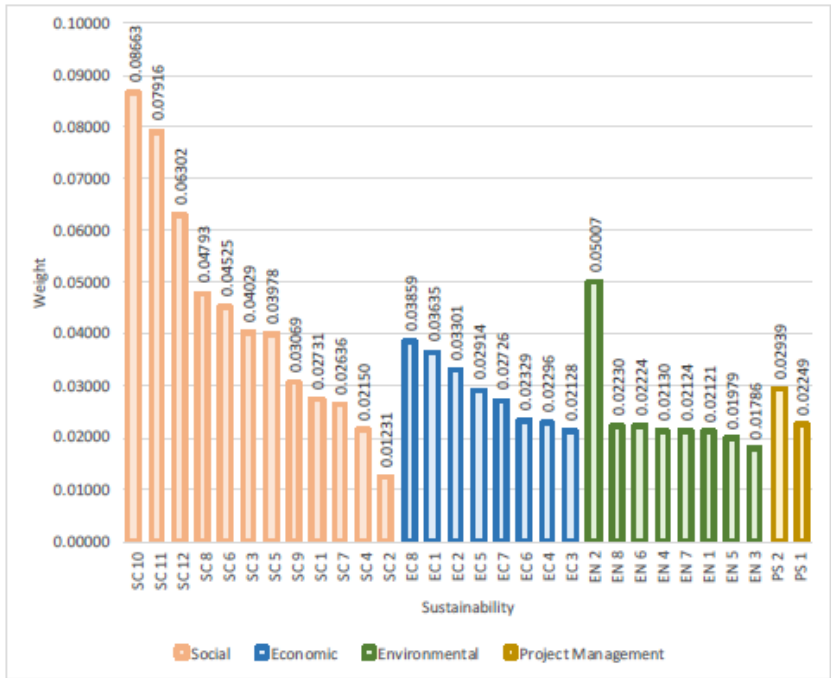

d: Weight of sustainability attributes for the PESTELMacro environment level

\section{Figure 3}

The weight of sustainability attributes 


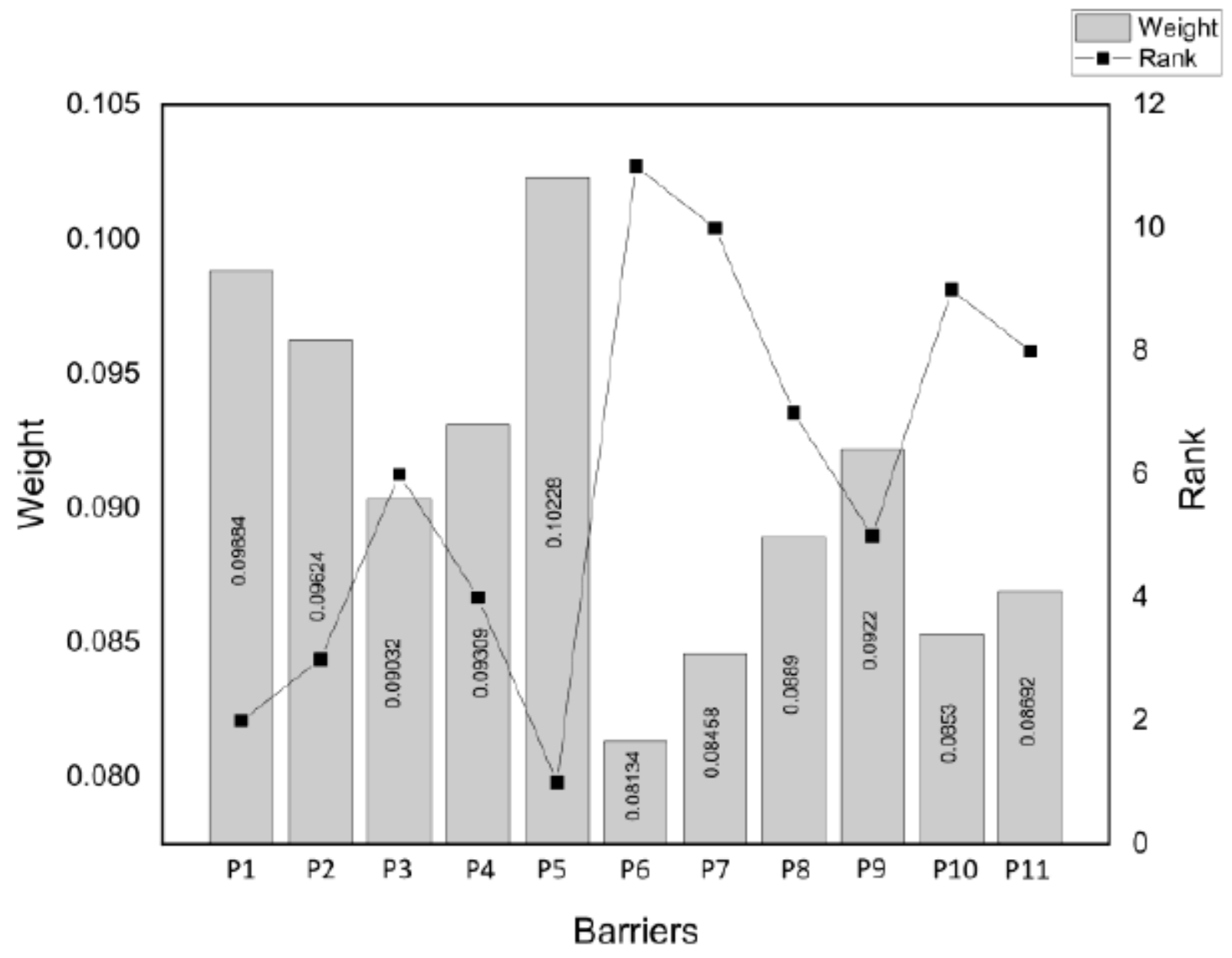

Figure 4

The weight and rank of barriers at the project level 


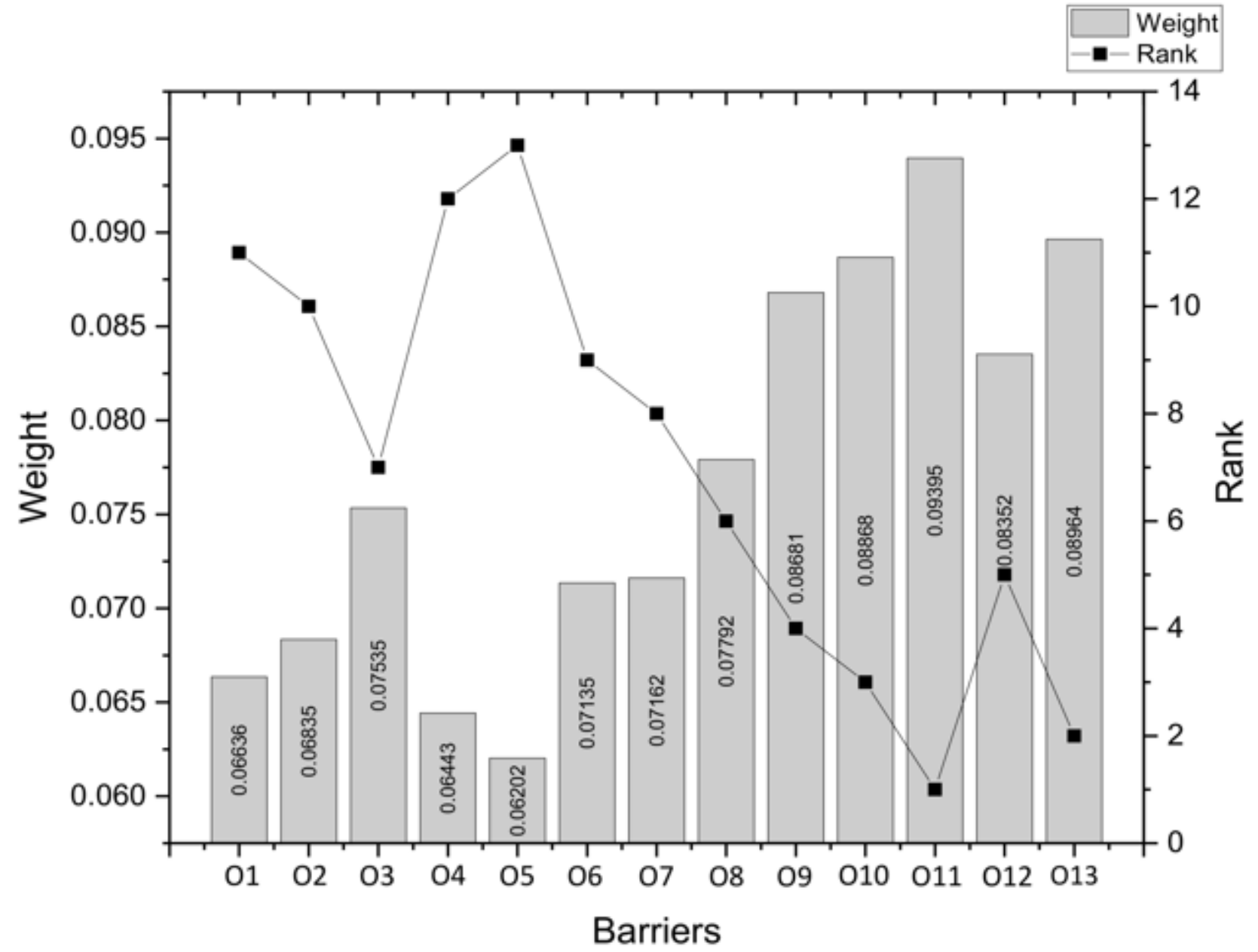

Figure 5

The weight and rank of barriers at the organizational level 


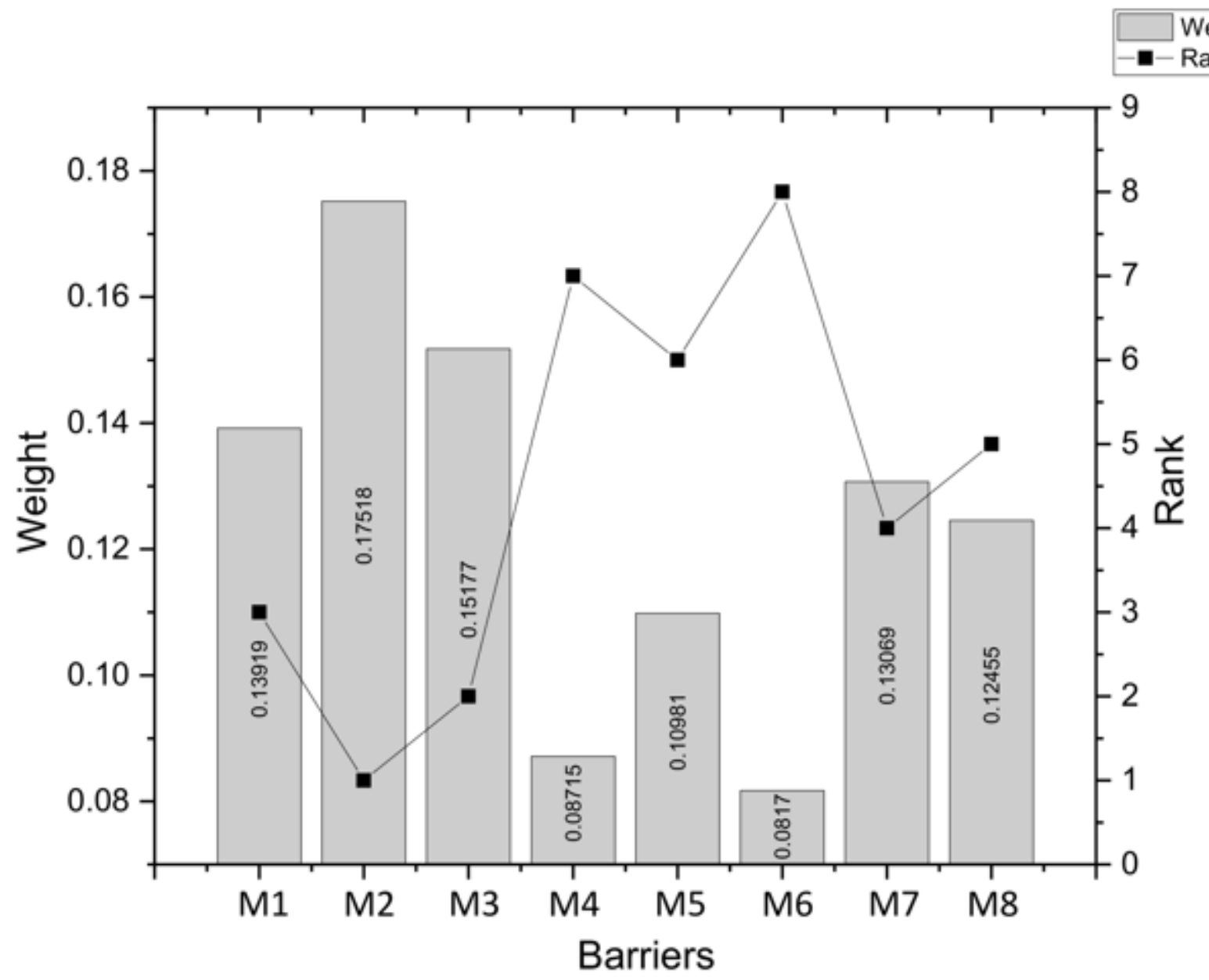

Figure 6

The weight and rank of barriers at the market level 


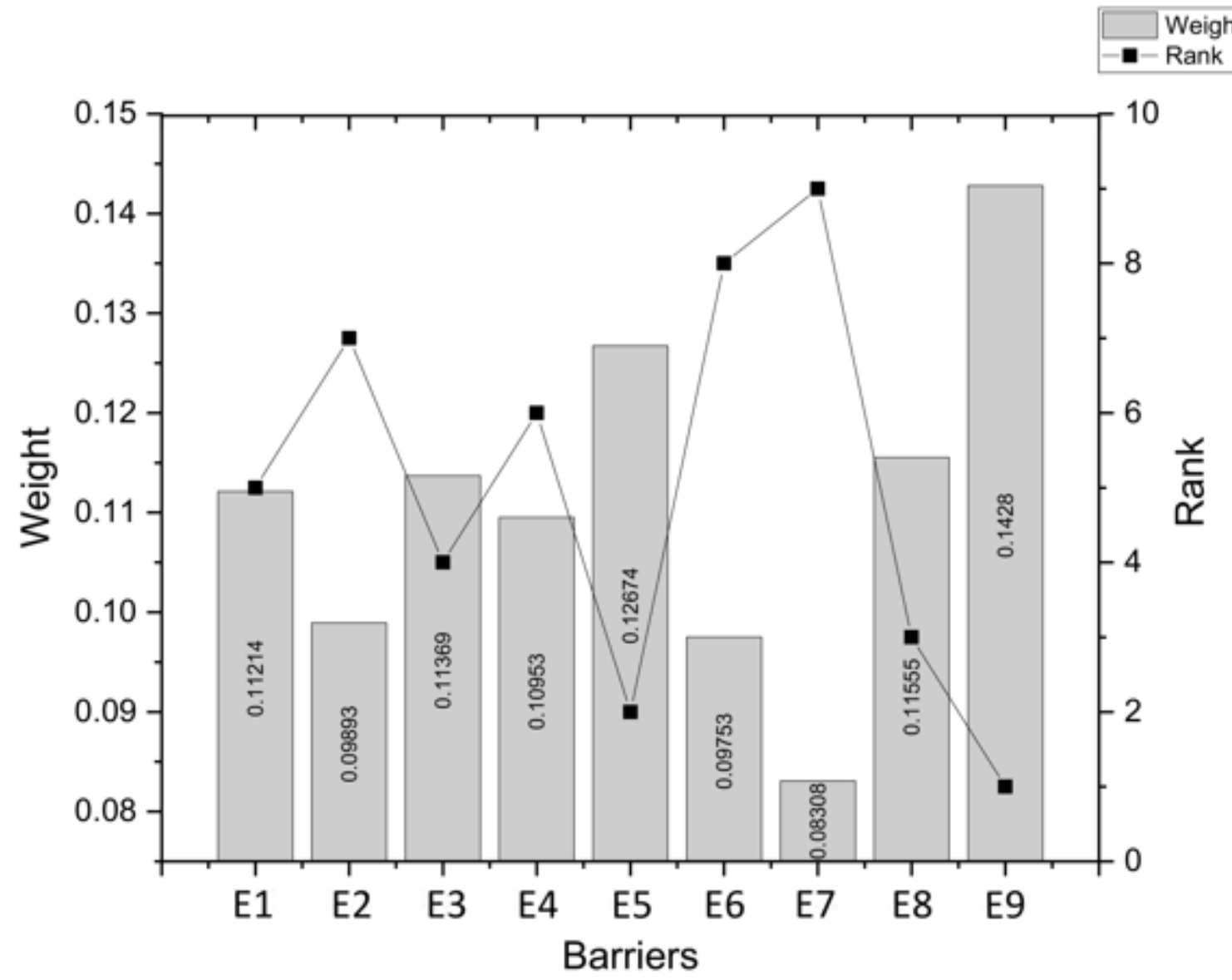

Figure 7

The weight and rank of barriers at the PESTEL-Macro Environment

\section{Supplementary Files}

This is a list of supplementary files associated with this preprint. Click to download.

- Appendix.docx 